\title{
Modeling and Design for a Novel Adaptive Voltage Positioning (AVP) Scheme for Multiphase VRMs
}

\author{
Martin Lee, Dan Chen, Fellow, IEEE, Kevin Huang, Chih-Wen Liu, Senior Member, IEEE, and Ben Tai
}

\begin{abstract}
Adaptive voltage positioning (AVP) has been used in multiphase voltage regulator module (VRM) applications. A novel scheme, called AVP +, is analyzed in this paper. Small signal model is used to look into the control performance issues such as output impedance and stability. The model has been verified in the experiments and simulations. Compared to a conventional AVP schemes, the present scheme provides better stability margin and outputimpedance performance. This is especially true for the prevailing trend of using ceramic output capacitors and high switching frequency. The focus of the present paper is the small-signal modeling for control loop design using the AVP + scheme which was never analyzed before. And the comparisons were made between AVP+ and AVP - on the stability and output impedance performance.
\end{abstract}

Index Terms-Adaptive voltage positioning (AVP)+ control, constant output impedance, stability, voltage regulator.

\section{INTRODUCTION}

A $\mathrm{N}$ ADAPTIVE voltage positioning (AVP) scheme has been used in multiphase synchronous rectifier buck converter topology for satisfying the power requirements of Intel's CPUs [1], [2]. The use of such a scheme normally leads to lower power dissipation in the CPU and smaller output capacitors required in the power converter circuit.

It has been pointed out that to achieve AVP, the closed-loop small-signal output impedance of the converter circuit should be a constant value which is specified by Intel's requirements [3]-[6]. The goal of the feedback design is therefore to perform a desirable output impedance characteristic while still maintaining feedback stability margin and good line regulation.

Fig. 1 shows a simplified diagram of an AVP control scheme commonly used to realize active droop control [7]-[9]. In the diagram, the load current signal is fed back and summed with the output voltage to be fed through $Z_{2}$ into the inverting input of the error amplifier. Most existing schemes employ this control strategy [10], [11]. This general scheme will be called the AVP - scheme for the fact that the feedback signal is connected to the inverting side of the error amplifier. Another scheme, called AVP+ in the present paper, was used in [12] and [13]

Manuscript received August 14, 2007; revised November 5, 2007. Published July 7, 2008 (projected). This work was supported by the National Science Council of Taiwan, R.O.C., by Awards NSC 94-2213-E-002-122 and NSC 96-2221-E-002-291-NY2 and by a research contract from Richtek Technology Corporation, Taiwan, to National Taiwan University. Recommended for publication by Associate Editor Y. C. Liang.

M. Lee, D. Chen, K. Huang, and C.-W. Liu are with the Department of Electrical Engineering, National Taiwan University, Taipei 10617, Taiwan, R.O.C.

B. Tai is with the RichTek Technology Corporation, Chubei City, Hsinchu 30288, Taiwan, R.O.C.

Color versions of one or more of the figures in this paper are available online at http://ieeexplore.ieee.org.

Digital Object Identifier 10.1109/TPEL.2008.924822

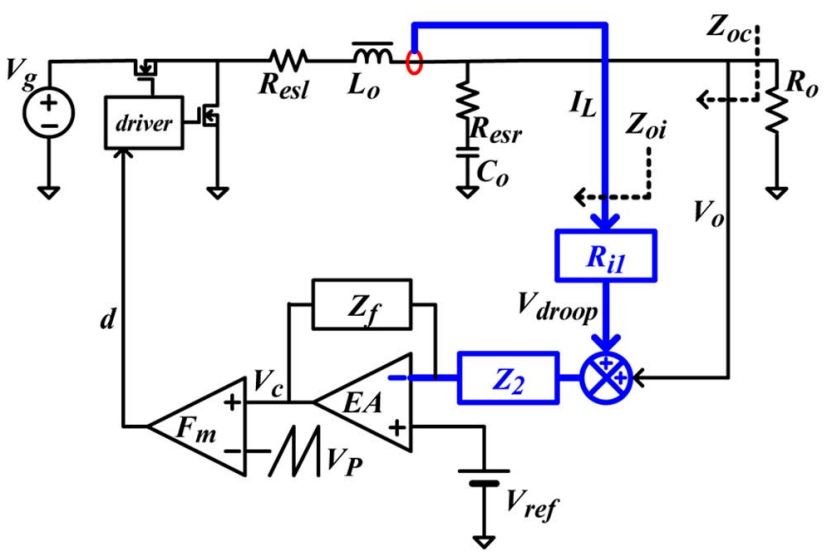

Fig. 1. VRM buck controller with AVP- control.

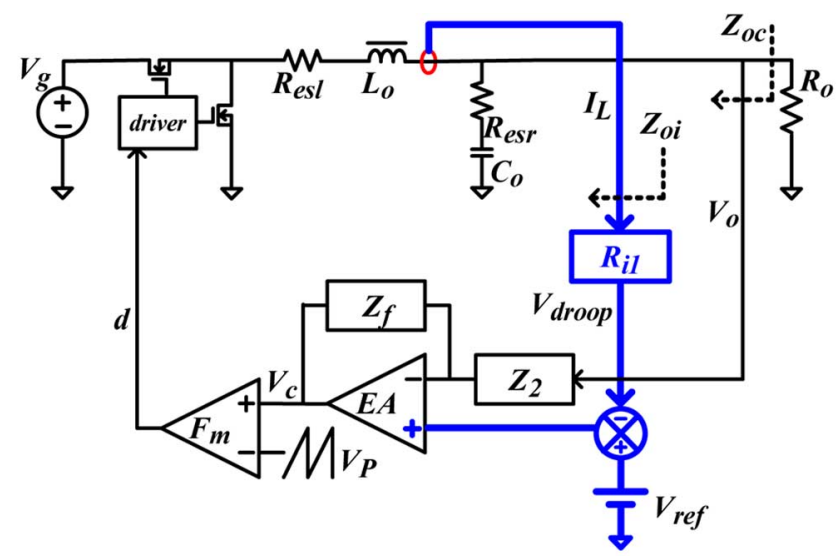

Fig. 2. VRM buck controller with AVP+ control.

but was never analyzed. The focus of this paper will be on the modeling and the design of the feedback for such a scheme. Fig. 2 shows the block diagram of the AVP+ control scheme. In the diagram, the sensed output inductor current information is subtracted from the reference voltage and fed into the noninverting terminal of the error amplifier EA. And the output voltage signal is fed into the inverting terminal. This scheme also allows the converter characteristic of output voltage declining with increasing load current as AVP requires. There is a subtle difference between the two control schemes that favors $\mathrm{AVP}+$ scheme, especially when ceramic capacitors are used in the output capacitors of the VRMs.

In this paper, the small-signal average model of buck converter circuit will be reviewed first. A model will then be developed for the AVP+. Both simulation and experimental results will be used to verify the model for a three-phase VRM. 


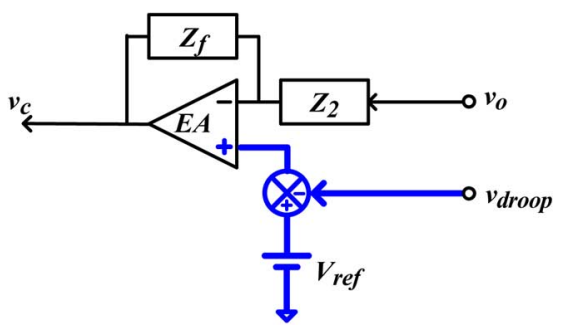

Fig. 3. Compensator circuit diagram.

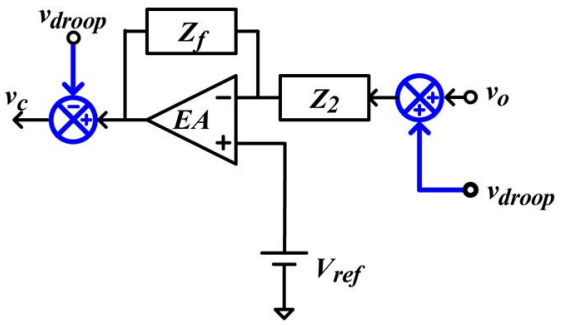

Fig. 4. Equivalent circuit diagram of that shown in Fig. 3.

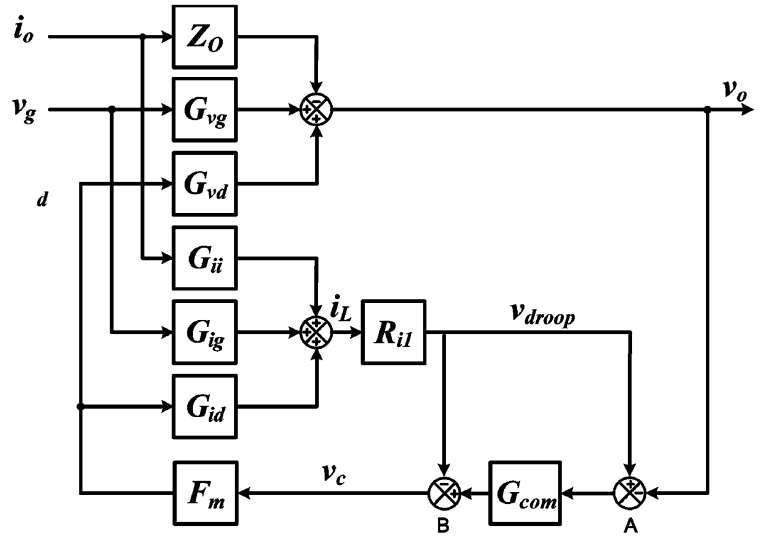

Fig. 5. Small-signal control block diagram of the AVP+ circuit shown in Fig. 2.

A comparison of the proposed AVP+ with conventional AVPis given at the end. The focus of the present paper is the smallsignal modeling for control loop design using the AVP+ scheme which was never analyzed before. And the comparisons were made between AVP+ and AVP- on the stability and output impedance performance.

\section{Control Block Diagram}

It has been pointed out that by proper switching frequency and component scaling, the control behavior of a multiphase converter can be represented by a simplified single-phase control circuit as shown in Fig. 2 [14].

\section{A. Compensator Transfer Functions}

From Fig. 2, the diagram around the error amplifier EA is isolated and redrawn in Fig. 3. From this figure, one can derive that

$$
v_{c}=\frac{Z_{f}}{Z_{2}} \cdot\left(v_{o}+v_{\text {droop }}\right)-v_{\text {droop }}
$$

TABLE I

Transfer Functions of THE CONTROL Block Diagram OF Fig. 4

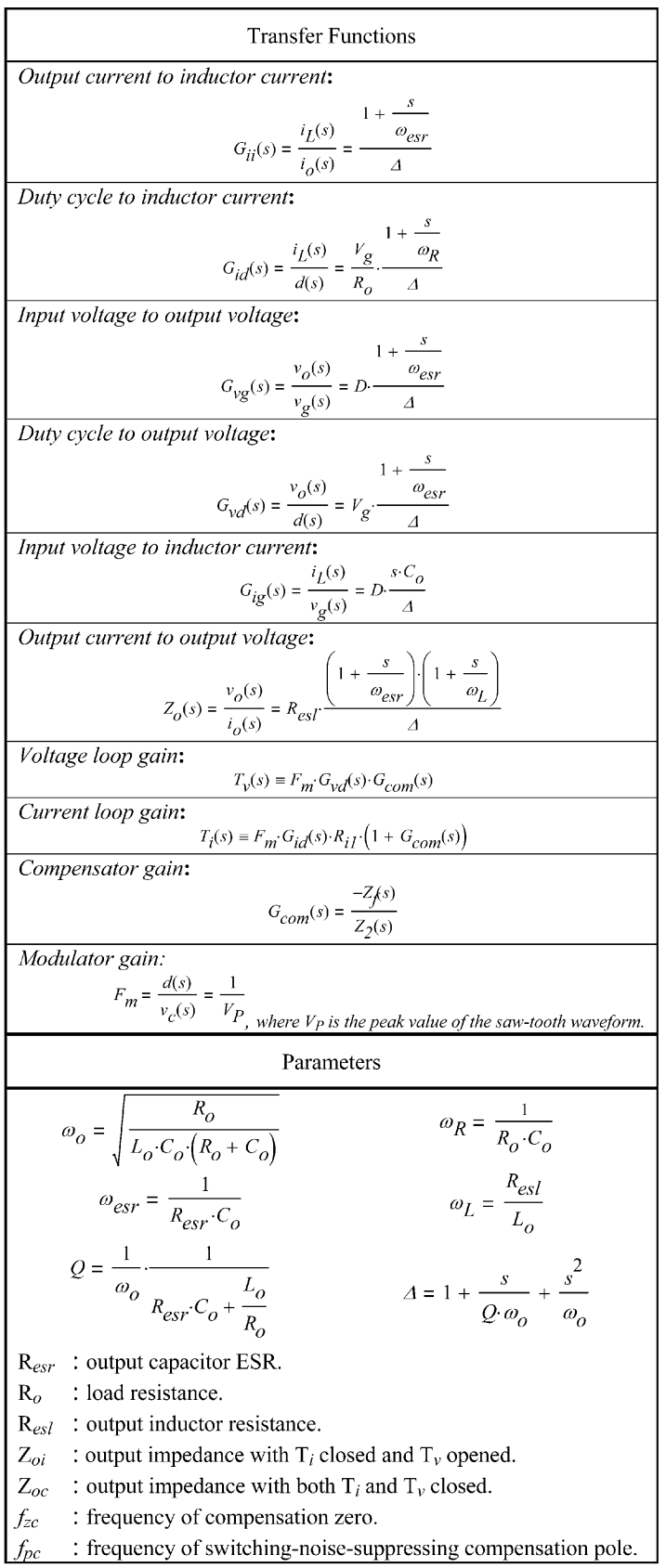

From this equation, the equivalent circuit of the error amplifier compensation circuit is shown in Fig. 4. The voltage droop caused by changing the $V_{\text {ref }}$ voltage has been represented by adding the two $v_{\text {droop }}$ inputs in the circuit shown in Fig. 4.

\section{B. Control Block Diagram}

The control scheme shown in Fig. 2 can be represented by the small-signal block diagram shown in Fig. 5. In the lower-right corner of the figure, the $v_{\text {droop }}$ signal is fed into Sumers A and B. This is to incorporate the equivalent circuit shown in Fig. 4 into the overall block diagram in Fig. 5. $G_{\text {com }}$ (s) is the transfer function of the compensator gain in Fig. 4, which is equal to $-Z_{f}(\mathrm{~s}) / Z_{2}$ (s). With the exception of the lower-right corner, the block diagram in Fig. 5 is similar to that of a conventional 


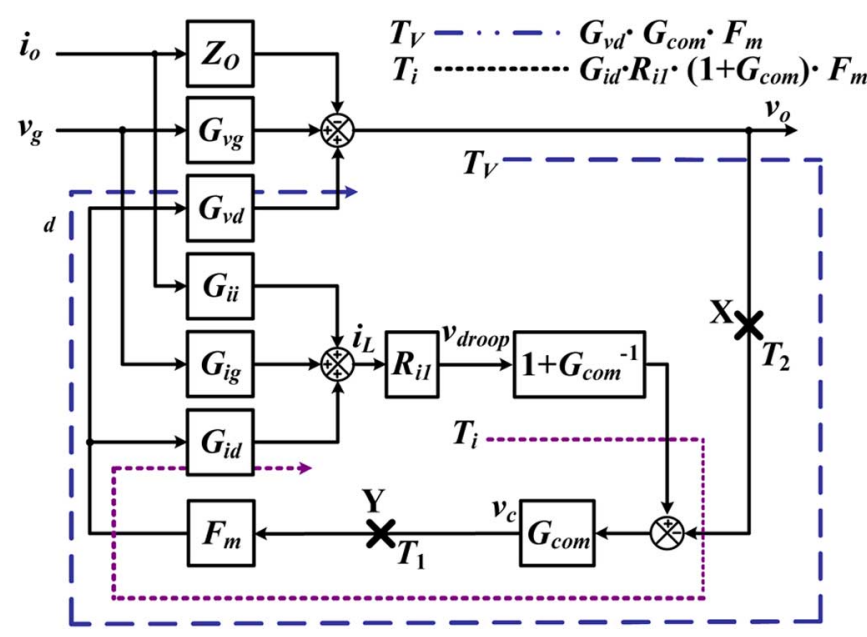

Fig. 6. Equivalent control block diagram of that shown in Fig. 5.

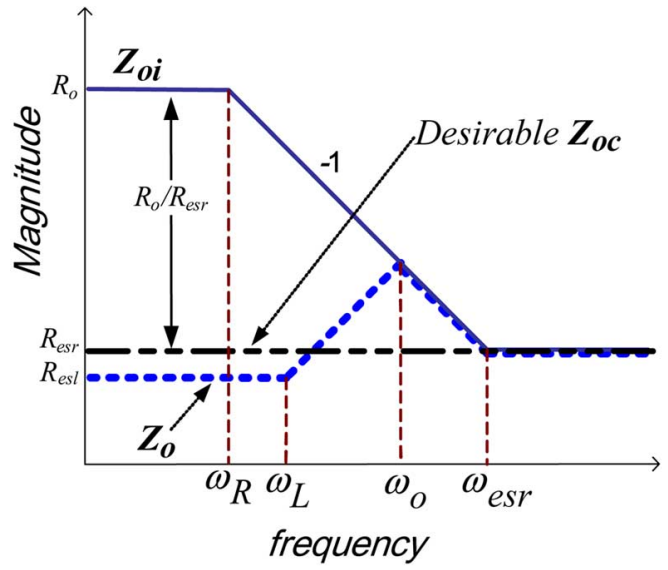

Fig. 7. Plots of $\left|Z_{o}\right|,\left|Z_{\mathrm{oi}}\right|$, and $\left|Z_{\mathrm{oc}}\right|$.

current-mode control buck converter which has been commonly used [15]. All the transfer functions are listed in Table I.

The diagram in Fig. 5 is further simplified into that in Fig. 6, where $1+G_{\mathrm{com}}^{-1}$ is the equivalent transfer function when Sumer $\mathrm{B}$ in Fig. 5 is eliminated.

\section{Useful Equations}

Loop gains: From Fig. 6, two loop gain functions, $T_{i}$ (s) and $T_{v}(s)$, are defined as follows:

$$
\begin{aligned}
& T_{v}(s) \equiv F_{m} \cdot G_{v d}(s) \cdot G_{\mathrm{com}}(s) \\
& T_{i}(s) \equiv F_{m} \cdot G_{i d}(s) \cdot R_{i l} \cdot\left(1+G_{\mathrm{com}}(s)\right) .
\end{aligned}
$$

By applying the Mason's gain formula, the two loop gains, $T_{1}$ (s) and $T_{2}(\mathrm{~s})$, evaluated at points $\mathrm{X}$ and $\mathrm{Y}$ respectively, are shown as follows.

Converter output impedance transfer functions:

$$
\begin{aligned}
& T_{1}(s)=T_{1}(s)+T_{v}(s) \\
& T_{2}(s)=\frac{T_{v}(s)}{1+T_{i}(s)} .
\end{aligned}
$$

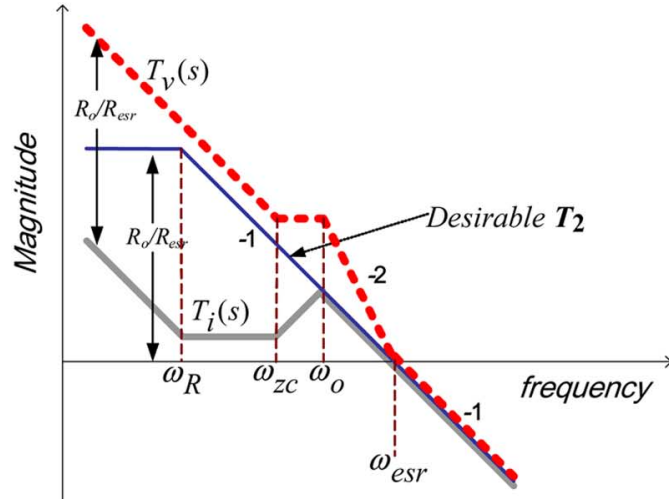

(a)

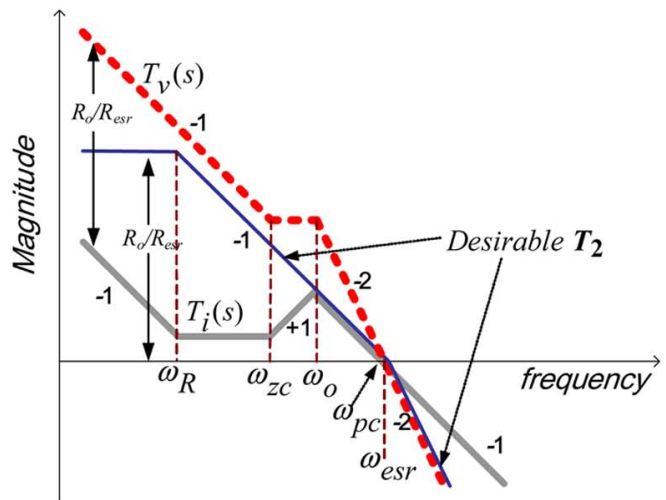

(b)

Fig. 8. Plots of $\left|T_{i}\right|,\left|T_{v}\right|$, and $\left|T_{2}\right|$. (a) Noise-suppression pole $\omega_{\mathrm{pc}}$ is much larger than $\omega_{\text {esr }}$. (b) Noise-suppression pole $\omega_{\text {pc }}$ is placed at $\omega=\omega_{\text {esr }}$.
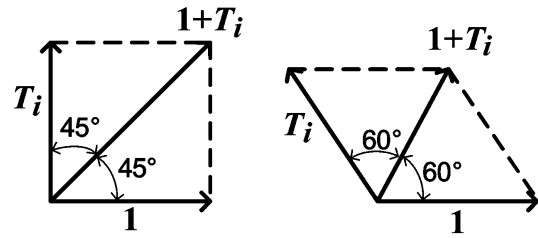

Fig. 9. Vector summation of $1+T_{i}$.

The output impedance transfer function with current loop closed but voltage loop opened is expressed as

$$
Z_{o i}(s)=\frac{Z_{o}(s)\left(1+T_{i}(s)\right)+F_{m} \cdot G_{i i}(s) G_{v d}(s) \cdot R_{i l}}{1+T_{i}(s)} .
$$

The output impedance transfer function with both the currentand the voltage-loop closed is expressed as

$$
Z_{o c}(s)=\frac{Z_{o}(s)\left(1+T_{i}(s)\right)+F_{m} \cdot G_{i i}(s) G_{v d}(s) \cdot R_{i l}}{1+T_{i}(s)+T_{v}(s)} .
$$

Fig. 7 shows the comparison plots of $\left|Z_{o}\right|,\left|Z_{\mathrm{oi}}\right|$, and $\left|Z_{\mathrm{oc}}\right|$. It can be seen the current loop alone actually increases the output impedance. Only when the voltage loop is also closed will the output impedance be brought down. Based on (8), the output 


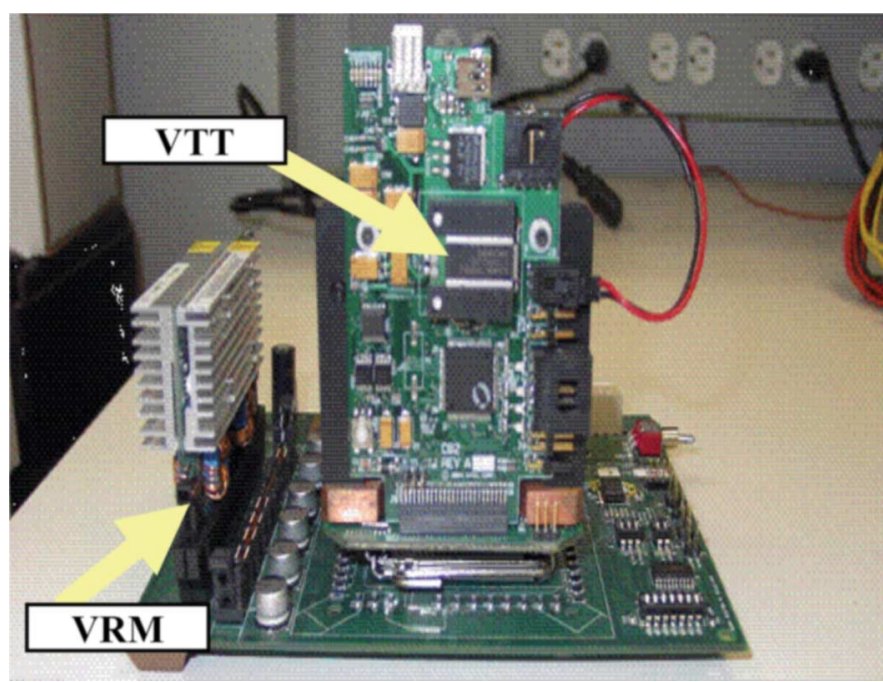

Fig. 10. Experimental hardware with VTT tool.

impedance $Z_{\mathrm{oc}}$ can be brought to constant output impedance shown by the "desirable $Z_{\mathrm{oc}}$," if a proper $T_{2}$ is used [7].

\section{DESIGN FOR A CONSTANT OUTPUT IMPEDANCE FOR AVP+}

It has been pointed out that constant output impedance is required to accomplish AVP. In this section, discussion will be given to feedback design to accomplish such a goal. As results of accomplishing this goal, other converter performances such as converter stability and audio-susceptibility are affected. These performances will be taken into considerations in the discussion.

The relationships between $Z_{\mathrm{oc}}(\mathrm{s})$ and $Z_{\mathrm{oi}}(\mathrm{s})$ can be derived as

$$
Z_{\mathrm{oc}}=\frac{Z_{\mathrm{oi}}(s)}{1+T_{2}(s)}
$$

\section{A. Desirable $T_{2}(s)$ to Accomplish a Constant Output Impedance}

Using (2), (3), and (5), if $\left|T_{i}\right| \gg 1$ and $\left|G_{\text {com }}\right| \gg 1, T_{2}$ is approximated as follows:

$$
T_{2}(s) \cong \frac{R_{o}}{R_{i 1}} \cdot \frac{1+\frac{s}{\omega_{\text {ess }}}}{1+\frac{s}{\omega_{R}}} .
$$

To achieve a constant $Z_{\mathrm{oc}}$ as shown in Fig. 7, $T_{2}$ must satisfy the following two conditions:

1) $\mathrm{R}_{i 1}$ is set to be $R_{\text {esr }}$ in (9).

2) $\left|T_{2}\right| \gg 1$ for $f<f_{\text {esr }}$.

It can be seen that $T_{2}$ is independent of $G_{\mathrm{com}}$ as long as the two assumptions, $\left|T_{i}\right| \gg 1$, and $\left|G_{\text {com }}\right| \gg 1$, hold. Therefore, one can design the compensation function $G_{\text {com }}$ to achieve a good $T_{2}$ stability margin and retain a constant output impedance performance. The two assumptions, $\left|T_{i}\right| \gg 1$ and $\left|G_{\mathrm{com}}\right| \gg 1$, are generally true for frequency much lower than $f_{\text {esr }}$ because a compensating pole is normally placed at dc frequency. This will be explained later in Section III-B.

\section{B. Compensation Design for AVP}

Beside output impedance, two other key issues, i.e., the stability and the audio-susceptibility, need to be taken into consid-

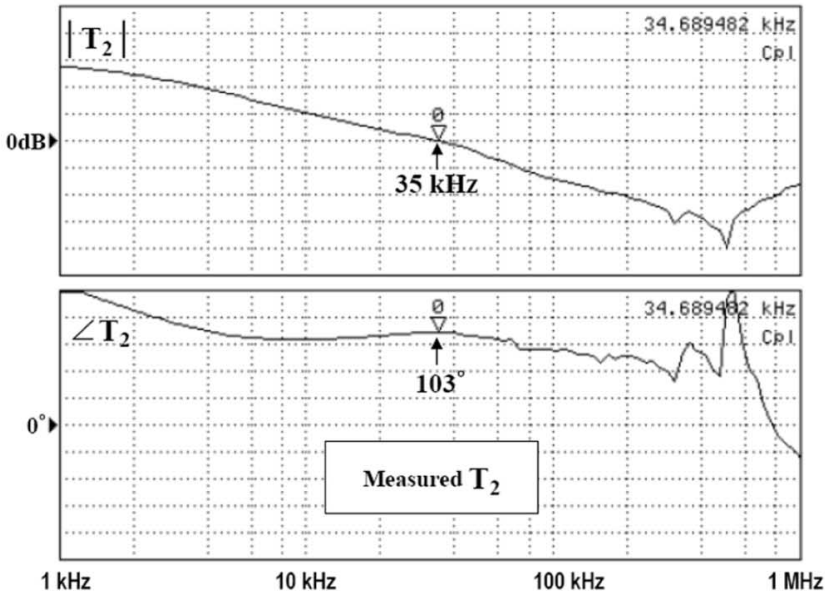

(a)

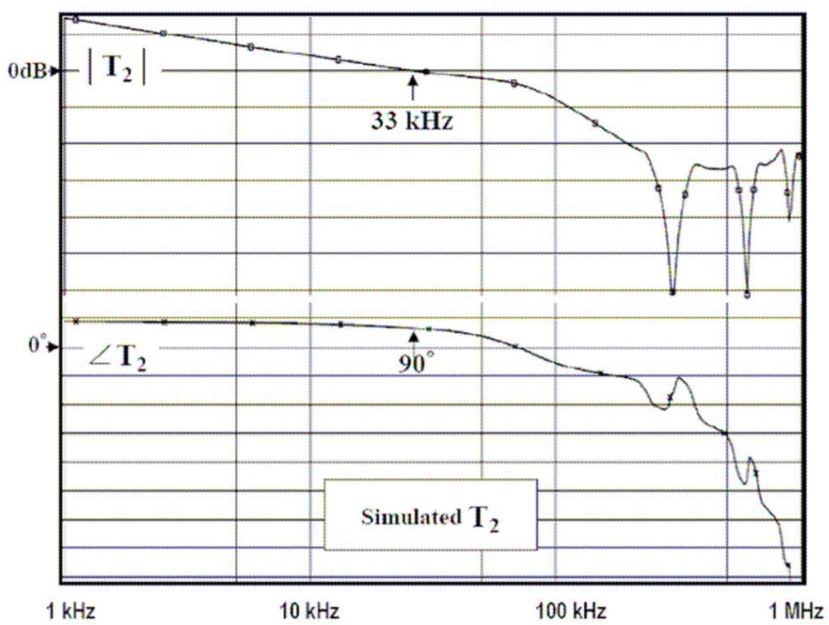

(b)

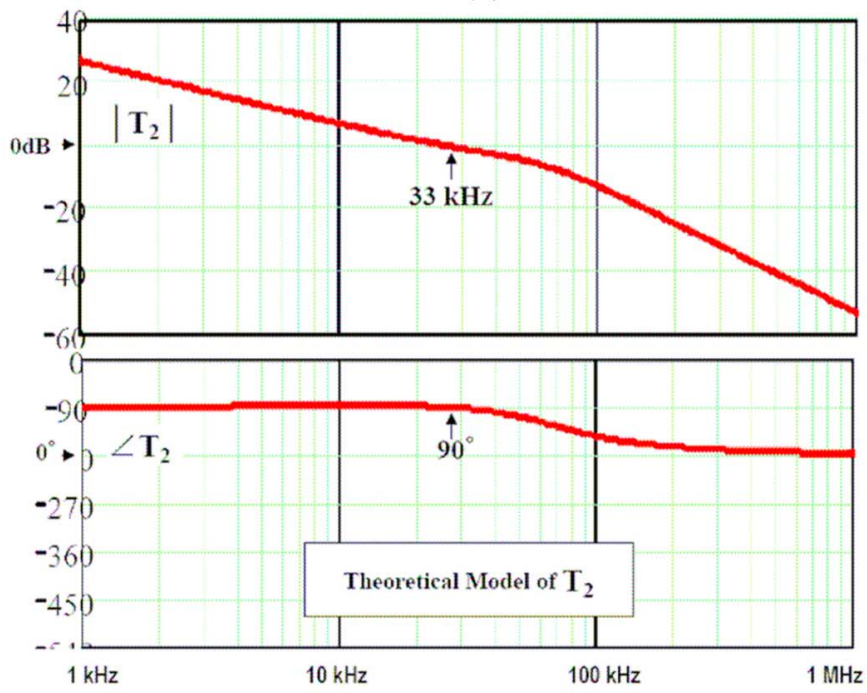

(C)

Fig. 11. Utter loop gain. (a) Measured $T_{2}$, (b) simulated $T_{2}$, and (c) theoretical model of $T_{2}$

erations. As described previously, $T_{2}$ is unchanged by the compensation $G_{\text {com }}$ as long as $\left|G_{\text {com }}\right|$ and $\left|T_{i}\right|$ are both much greater than 1 . Therefore, a low-frequency compensation pole (integrator) can be used in $G_{\text {com }}$ to boost the low-frequency gain of 


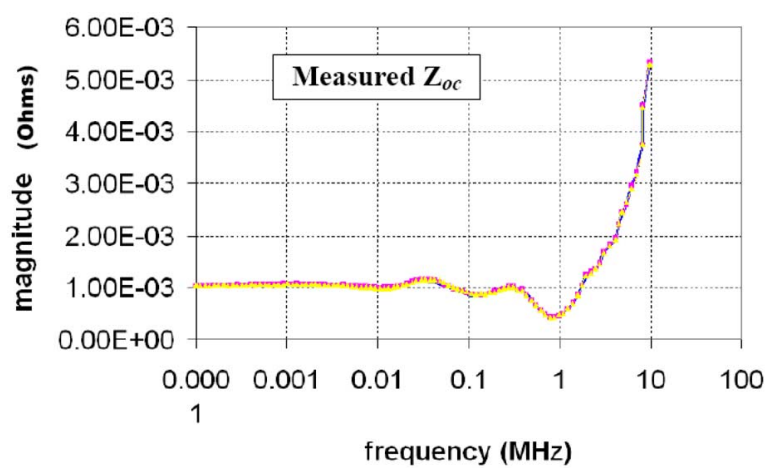

(a)

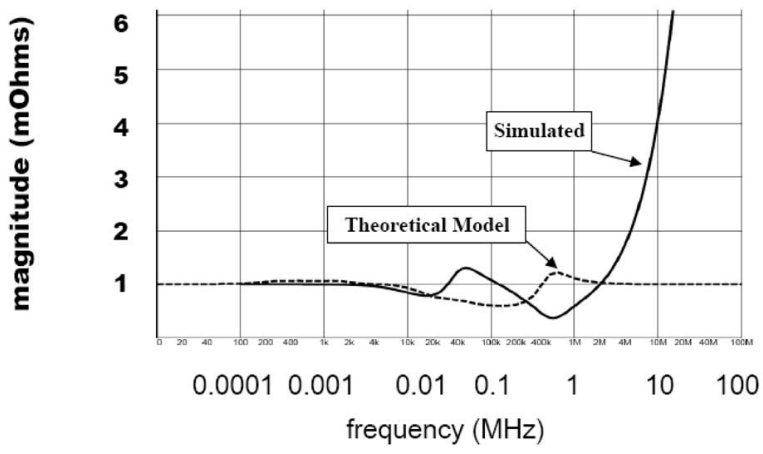

(b)

Fig. 12. Closed-loop output impedance. (a) Measured $\left|Z_{\mathrm{oc}}\right|$ and (b) theoretical model of $\left|Z_{\mathrm{oc}}\right|$ and simulated $\left|Z_{\mathrm{oc}}\right|$ plot including parasitic inductance of $100 \mathrm{pH}$.

$T_{i}$ and $T_{v}$ and consequently $T_{1}$ so that audio-susceptibility performance can be improved without much affecting $T_{2}$ characteristics and the close-loop output impedance performance $Z_{\mathrm{oc}}$. A compensation zero $f_{\mathrm{zc}}$ should also be placed near the resonance frequency $f_{o}$ to stabilize the loop gain $T_{1}$. Finally, a compensation pole $f_{\text {pc }}$ is normally used to suppress switching-frequency noise. Placement of $f_{\mathrm{pc}}$ is flexible, depending on the amount of the noise attenuation required [7], [16]. However, if $f_{\mathrm{pc}}$ is too close to $f_{\mathrm{esr}}$, then $f_{\mathrm{pc}}$ may have noticeable effects on the $T_{1}$ and $T_{2}$ stability margin, and $Z_{\mathrm{oc}}$ may spike near $f_{\mathrm{esr}}$. This will be discussed in detail in Section III-D.

\section{Crossover Frequency}

From the discussion in the last section, $T_{2}$ crosses over at $f_{\text {esr }}$ as shown in Fig. 8. As a result, $T_{i}$ and $T_{v}$ must also cross over at $f_{\text {esr }}$. Because of (5), the $T_{2}$ value for frequency beyond $f_{\text {esr }}$ can be decreasing with -1 slope or -2 slope depending on whether a noise-suppressing pole is placed near $f_{\text {esr }}$. Fig. 8 shows the plots for both cases. In either case, $Z_{\mathrm{oc}}$ is essentially the same except for frequency near $f_{\text {esr }}$. $\left|Z_{\text {oc }}\right|$ is more likely to exhibit a spike near $f=f_{\text {esr }}$ for the case in Fig. 8(b). The $T_{2}$ stability margin will also be affected by the crossover slope of $T_{2}$.

A quick explanation of $T_{2}$ behavior is given below. From (5), for low frequency when $\left|T_{i}\right| \gg 1, T_{2} \approx T_{v} / T_{i}$, for frequency when $\left|T_{i}\right| \ll 1, T_{2} \approx T_{v}$. Near the cross over frequency of $T_{i}$, where $\left|T_{i}\right| \approx 1, T_{2}$ behavior depends on the phase angles of $T_{i}$ and $T_{v}$ at that frequency. This affects the $T_{2}$ stability phase margin. And according to (8), the $T_{2}$ phase margin affects the $Z_{\mathrm{oc}}$ behavior near $f_{\text {esr }}$. Spiking of $\left|Z_{\mathrm{oc}}\right|$ characteristics may

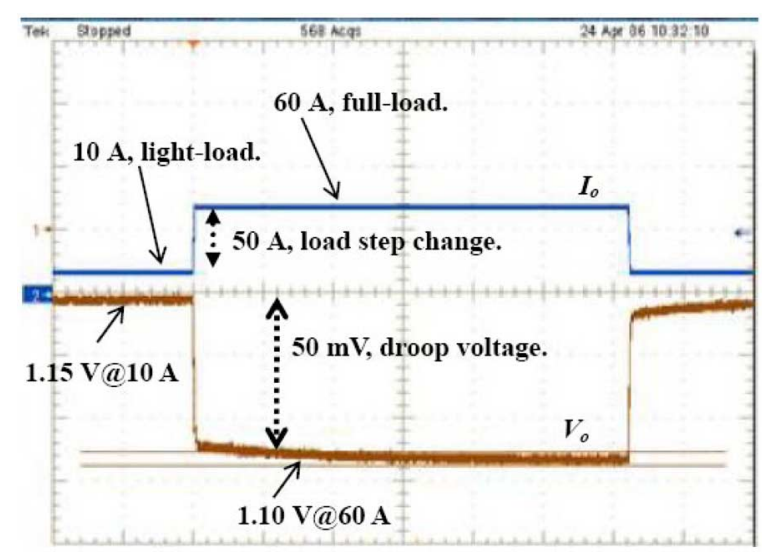

Fig. 13. Measured waveforms of output voltage and output current for AVP+.

TABLE II

KEY COMPONENT PARAMETERS FOR EXPERIMENT

\begin{tabular}{|ll|}
\hline \multicolumn{1}{|c|}{ Circuit Parameters } \\
\hline $\mathrm{C}_{o}:$ Oscon, $(560 \mu \mathrm{F} / 7 \mathrm{~m} \Omega) \times 10$, \\
$f_{\text {esr }}: 40.62 \mathrm{kHz}$, \\
$\mathrm{L}_{o}:: 320 \mathrm{nH}$, per-phase, \\
$f_{s w}: 300 \mathrm{kHz}$ \\
Controller: RT8800 by Richtek Inc., \\
MOSFETs: FAN0N9B \\
\hline
\end{tabular}

TABLE III

Key COMPONENT PARAMETERS FOR SIMPLIS SiMULATION

\begin{tabular}{|ll|}
\hline \multicolumn{1}{|c|}{ Circuit Parameters } \\
\hline \multicolumn{1}{|c|}{ CASE I. using large capacitor type } \\
\hline $\mathrm{C}_{o} \quad:$ Oscon, $(820 \mu \mathrm{F} / 12 \mathrm{~m} \Omega) \times 12 \rightarrow 9,840 \mu \mathrm{F} / 1 \mathrm{~m} \Omega$, \\
& $f_{\text {esr }}=16.17 \mathrm{kHz}$. \\
$\mathrm{L}_{o}$ & $: 470 \mathrm{nH}$, per-phase \\
$f_{s w}$ & $: 300 \mathrm{kHz}$ \\
$f_{p c}$ & $: 100 \mathrm{kHz}$ \\
\hline & \multicolumn{1}{c|}{$\mathrm{CASE} \mathrm{II.}$ using ceramic capacitors } \\
\hline $\mathrm{C}_{o}$ & $:$ Ceramic, $(100 \mu \mathrm{F} / 1.5 \mathrm{~m} \Omega) \times 2 \rightarrow 200 \mu \mathrm{F} / 0.75$ \\
& $\mathrm{~m} \Omega, f_{e s r}=1.1 \mathrm{MHz}$. \\
$\mathrm{L}_{o} \quad: 100 \mathrm{nH}$, per-phase \\
$f_{s w} \quad: 1 \mathrm{MHz}$ \\
$f_{p c} \quad: 300 \mathrm{kHz}$ \\
\hline $\mathrm{L}_{o} \quad:$ output inductance \\
$\mathrm{C}_{o} \quad:$ output capacitance \\
$\mathrm{R}_{e s r}:$ capacitance ESR \\
\hline
\end{tabular}

show up near $f_{\text {esr }}$ because of low $T_{2}$ stability margin. This will be explained in Section III-D.

\section{Behavior of $Z_{\mathrm{oc}}, T_{2}$, and $T_{1}$ Near $f_{\mathrm{esr}}$}

Near $f_{\text {esr }}$, the amplitude of $T_{i}$ is nearly unity. However, because of vector summation, $\left|1+T_{i}\right|$ can vary from 0 to 2 . Fig. 9 shows the vector summation of $\left|1+T_{i}\right|$ for the phases of $T_{i}$ are $90^{\circ}$ and $120^{\circ}$, respectively. If $T_{i}$ is close to $180^{\circ}$, then $\left|T_{2}\right|$ frequency response would have a peaking near $f_{\mathrm{esr}}$, according to (5). By the same argument, the $T_{2}$ phase angle at $f=f_{\text {esr }}$ affects $Z_{\mathrm{oc}}$ near $f_{\text {esr }}$ also according to (8). 


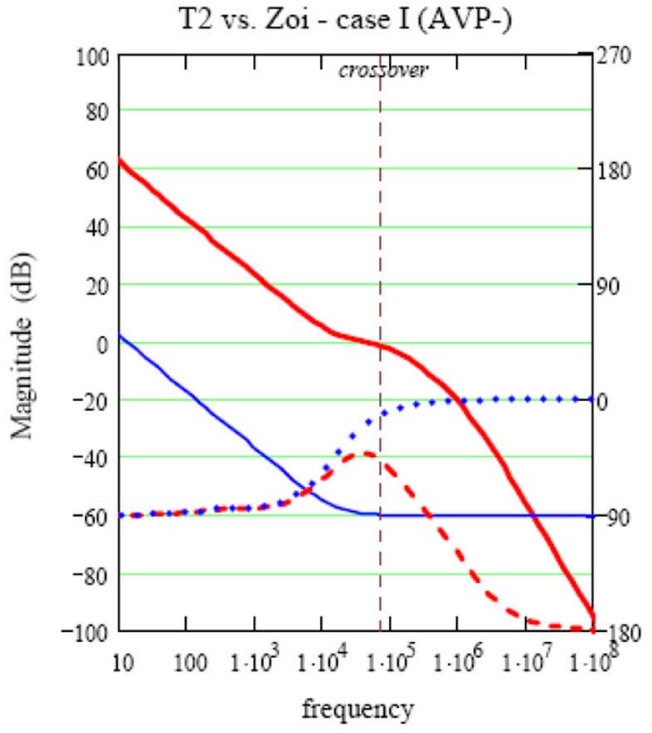

(a)

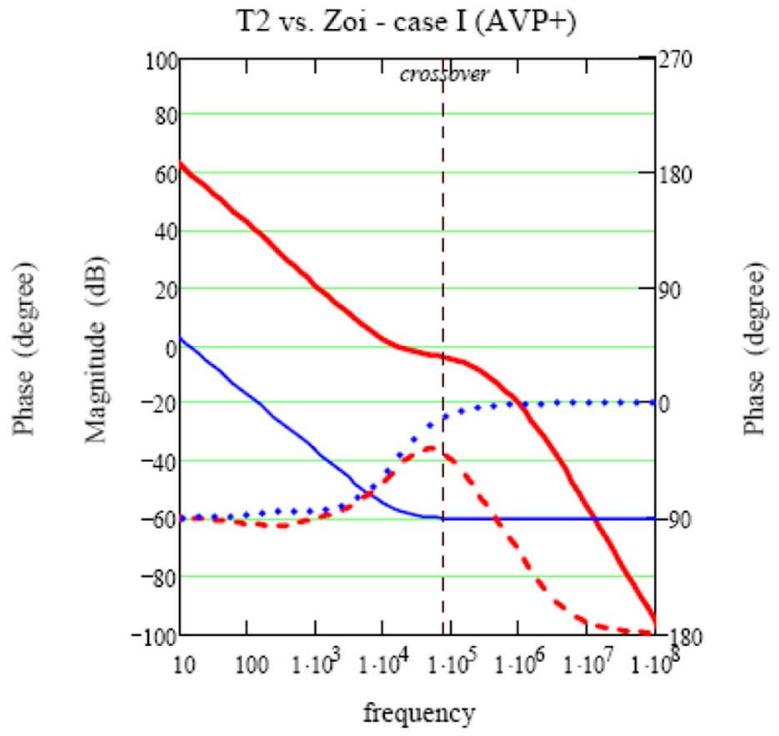

(b)

Fig. 14. Theoretical $T_{2}$ plots for case I (a) AVP- and (b) AVP+, when $f_{\mathrm{pc}} \gg f_{\mathrm{esr}}$.

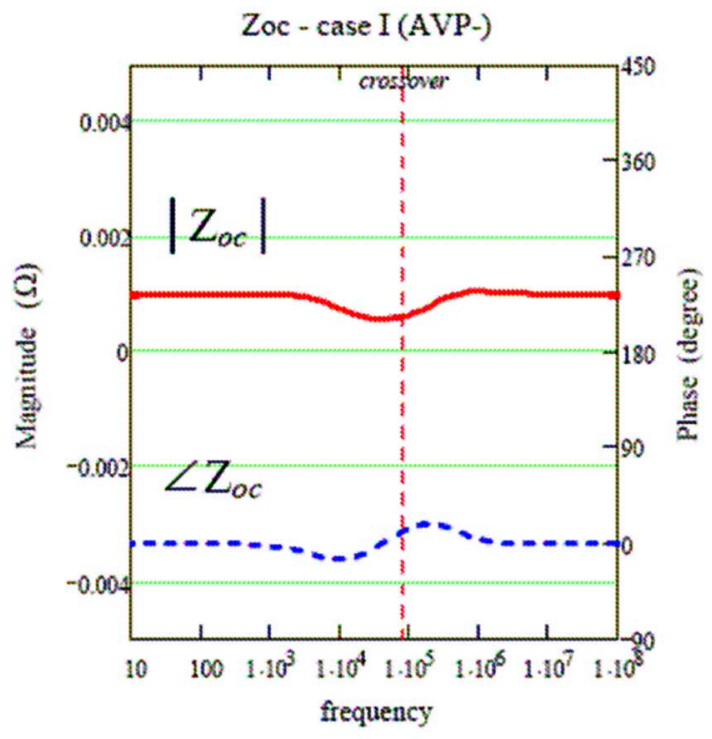

(a)

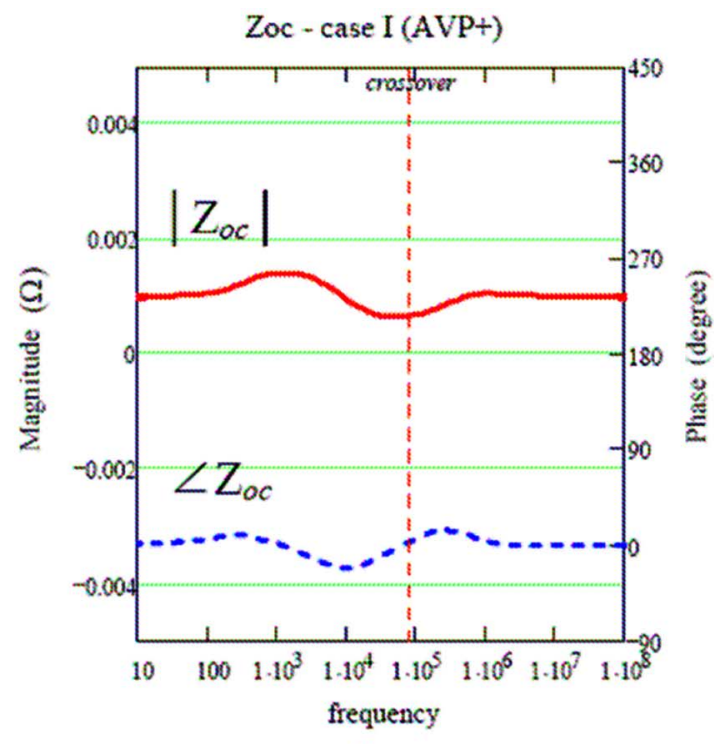

(b)

Fig. 15. Theoretical $Z_{\mathrm{oc}}$ plots for case I (a) AVP- and (b) AVP+, when $f_{\mathrm{pc}} \gg f_{\text {esr }}$.

Based on the design concerns given in this subsection, a converter was built for experimental verification to be explained in Section IV.

\section{EXPERIMENTAL RESULTS}

A three-phase interleaved buck converter was designed and tested to verify the model described above. Table II shows the circuit operating conditions and component values. A Cascade Systems Technology's Voltage Transient Tool (VTT) as a CPU load equipment was used to test the various circuit functions [17]. Fig. 10 shows the hardware. Fig. 11 not only shows the measured and the theoretical utter loop gain $T_{2}$ but also the simulation results of this magnitude. Fig. 12(a) shows the measured closed-loop output impedance $Z_{\mathrm{oc}}$ versus the frequency. It agrees well with the model at frequency below $1 \mathrm{MHz}$. The derivation at high frequencies was attributed to the parasitic inductance of the breadboard circuit trace. When a 100-pH parasitic inductor was used, both agree well. This is also confirmed by the SIMPLIS simulation results shown in Fig. 12(b). The load step change waveforms of the breadboard are shown in Fig. 13.

\section{COMPARISON OF AVP+ AND AVP-}

The design and analysis of AVP- are well discussed and developed in papers. For control loop design, the major difference between AVP- and AVP+ is the expressions for the current loop transfer function $T_{i}(\mathrm{~s})$. The equations for $T_{i}(\mathrm{~s})$ are as 


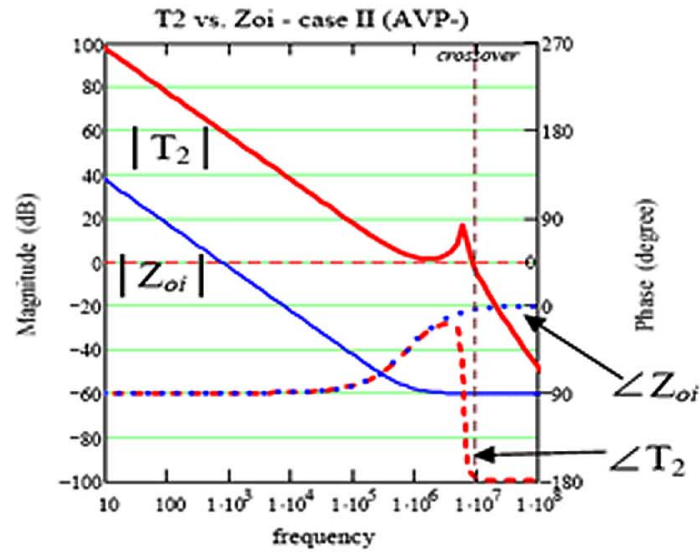

(a)

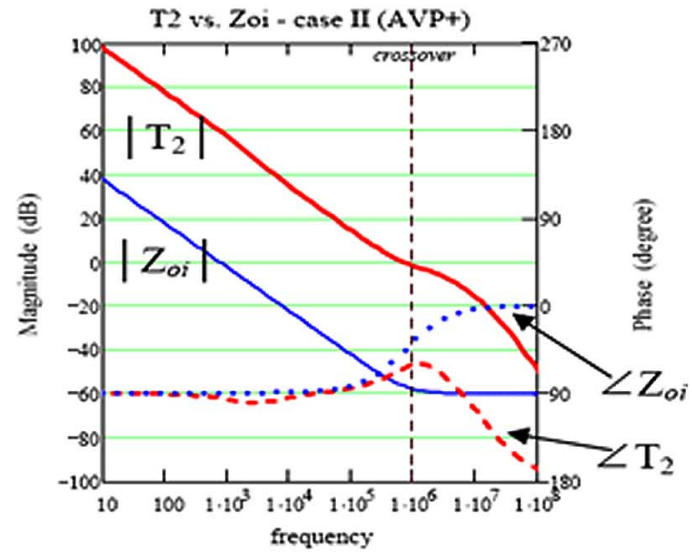

(b)

Fig. 16. Theoretical $T_{2}$ plots for case II (a) AVP- and (b) AVP+, when $f_{\mathrm{pc}}$ is near or less than $f_{\text {esr }}$.

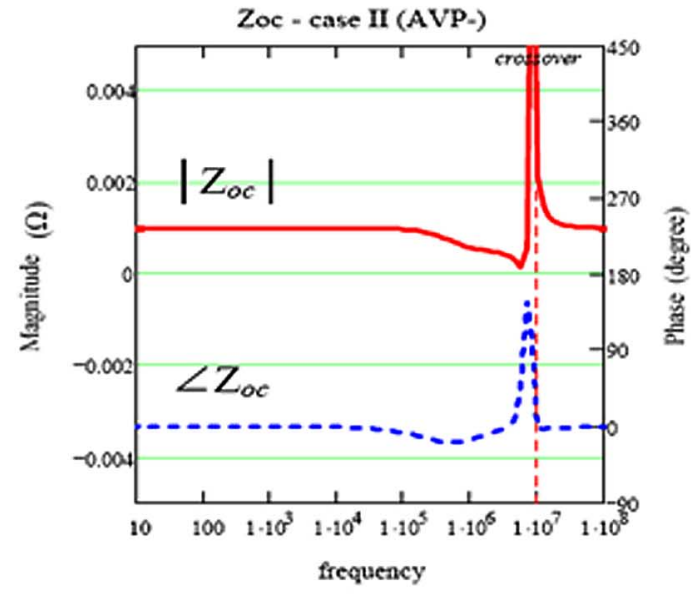

(a)

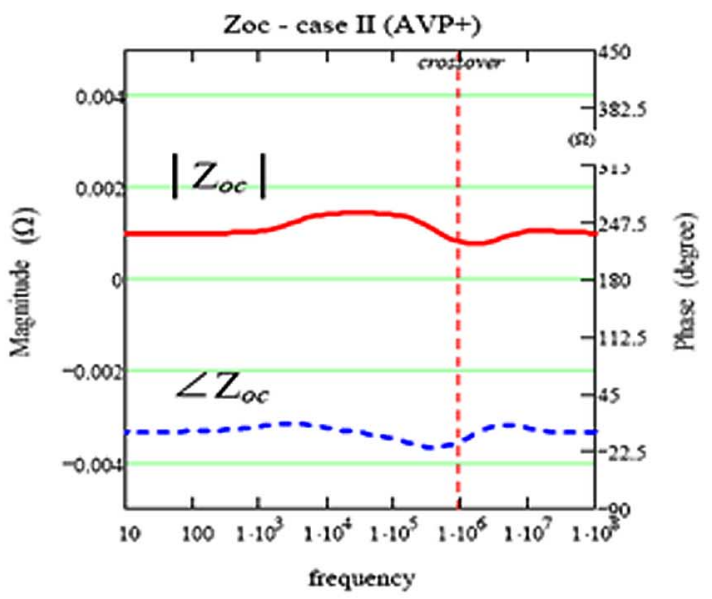

(b)

Fig. 17. Theoretical $Z_{\mathrm{oc}}$ plots for case II (a) AVP- and (b) AVP+, when $f_{\mathrm{pc}}$ is near or less than $f_{\text {esr }}$.

follows:

$$
\begin{array}{r}
T_{i}(s) \equiv F_{m} \cdot G_{i d}(s) \cdot R_{i 1} \cdot\left(1+G_{\mathrm{com}}(s)\right), \\
\text { for AVP }+ \\
T_{i}(s) \equiv F_{m} \cdot G_{i d}(s) \cdot R_{i 1} \cdot\left(1+G_{\mathrm{com}}(s)\right), \\
\text { for AVP }-.
\end{array}
$$

$T_{2}$ and $Z_{\mathrm{oc}}$ functions will be plotted for two practical cases using the model and the expression given above. In case I, large OSCAN capacitors were used in which $f_{\text {esr }}$ is relatively small compared to switching frequency. In case II, small ceramics capacitors were used in which $f_{\text {esr }}$ is close to the switching frequency.

In both cases, a noise-suppression compensation pole $f_{\mathrm{pc}}$ was used. To be effective, $f_{\mathrm{pc}}$ must be significantly below switching frequency. The exact component values of the two cases are listed in Table III.

As mentioned in Section III-B, a compensation pole $f_{\mathrm{pc}}$ may be used to suppress hardware switching-frequency noise in the circuit. To be effective, $f_{\mathrm{pc}}$ must be significantly lower than the switching frequency. If $f_{\mathrm{pc}} \gg f_{\mathrm{esr}}$, as case $\mathrm{I}$, then there is very little difference between AVP+ and AVP-. Figs. 14 and 15 show the $T_{2}$ and $Z_{\mathrm{oc}}$ plots for the two schemes. However, if $f_{\mathrm{pc}}$ is close to or even less than $f_{\mathrm{esr}}$, then that significantly degrades the $T_{2}$ stability margin, and $Z_{\mathrm{oc}}$ exhibits a spike near $f_{\text {esr }}$ for the AVP- but not AVP+, as shown in Figs. 16 and 17. This is because $f_{\mathrm{pc}}$ significantly affects $T_{i}$ phase angle at $f=f_{\text {esr }}$. As can be seen from Fig. 18(a), $\angle T_{i}$ is near $-180^{\circ}$ at $\left|T_{i}\right|$ zero crossovers for AVP-. From the discussing given in Section III-D, this means $T_{2}$ is near instability and $\left|Z_{\mathrm{oc}}\right|$ shows a spike. However, in Fig. 18(b), the AVP+ case, $T_{i}$ still has about an $80^{\circ}$ phase margin which means large $\left|T_{2}\right|$ stability phase margin and little $\left|Z_{\mathrm{oc}}\right|$ spike near $f_{\text {esr }}$. For the cases shown in Fig. 19, both AVP - and AVP+ exhibit a large margin at $\left|T_{i}\right|$ crossover frequency. This explains why there is very little difference between AVP+ and AVP - for this condition.

Simulation results: The simulations were run for a practical three-phase VRM to compare the two schemes, AVP+ and AVP-, under both cases I and II using SIMPLIS simulation tool [18]. For case I, there is a little difference between the two schemes. However, there are significant differences for case II as shown by the $T_{2}$ and $\left|Z_{\mathrm{oc}}\right|$ plots shown in Figs. 20-22. Simulation results confirm the theoretical predictions. Fig. 23 shows the load-step response of AVP + and AVP - for case II. It can be seen that AVP+ gives a better step response because of absence of output voltage and inductor current ringing which 


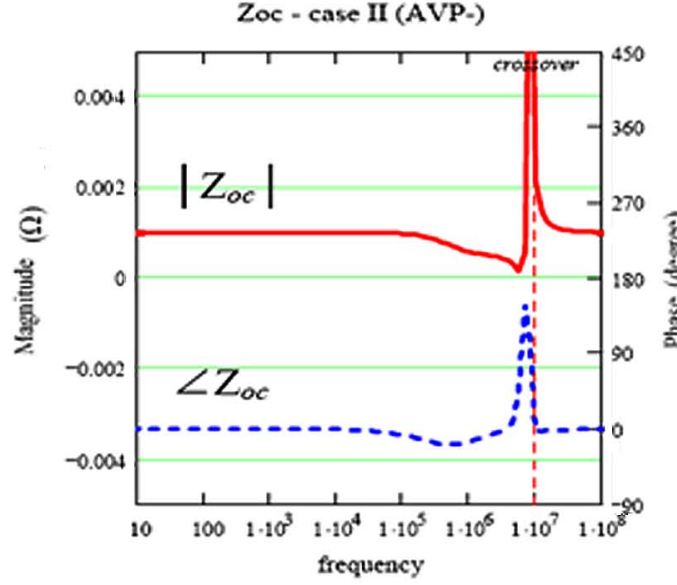

(a)

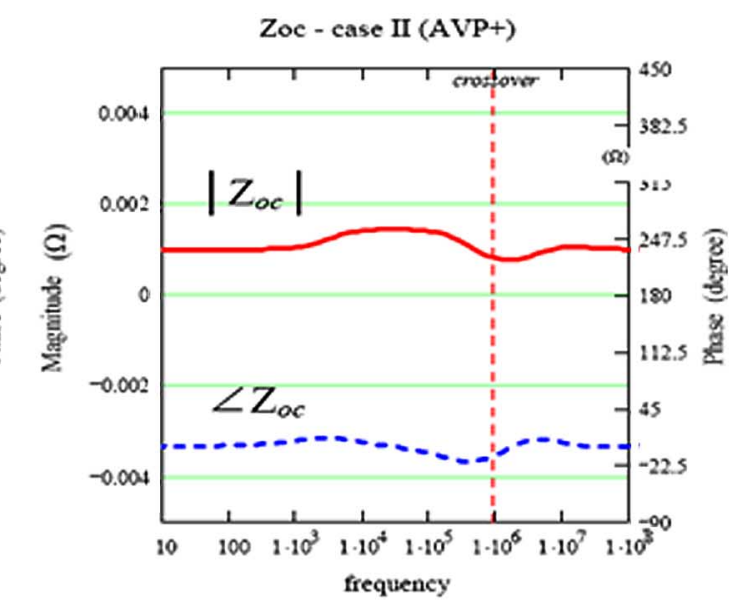

(b)

Fig. 18. Theoretical $T_{i}$ plots for case II (a) AVP - and (b) AVP+, when $f_{\mathrm{pc}}$ is near or less than $f_{\text {esr }}$.

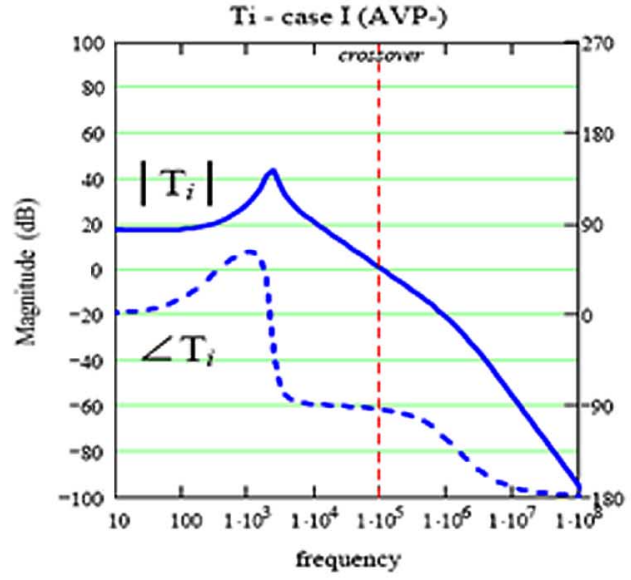

(a)

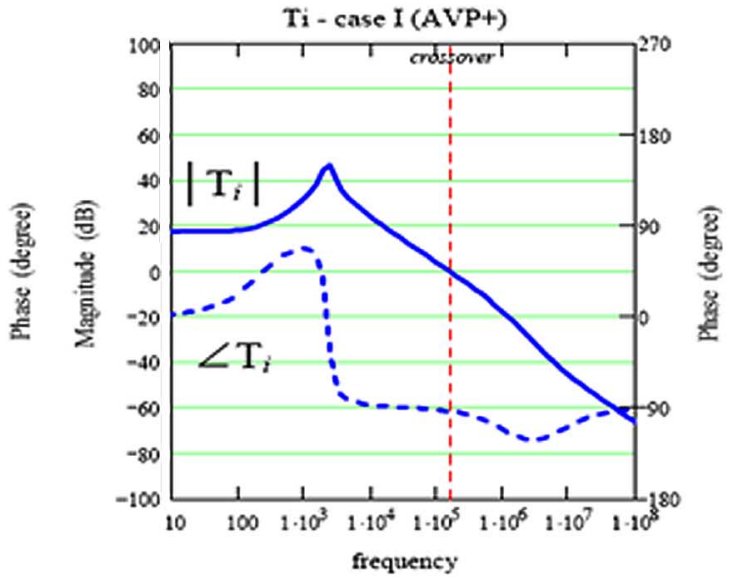

(b)

Fig. 19. Theoretical $T_{i}$ plots for case I (a) AVP- and (b) AVP+, when $f_{\mathrm{pc}} \gg f_{\text {esr }}$.

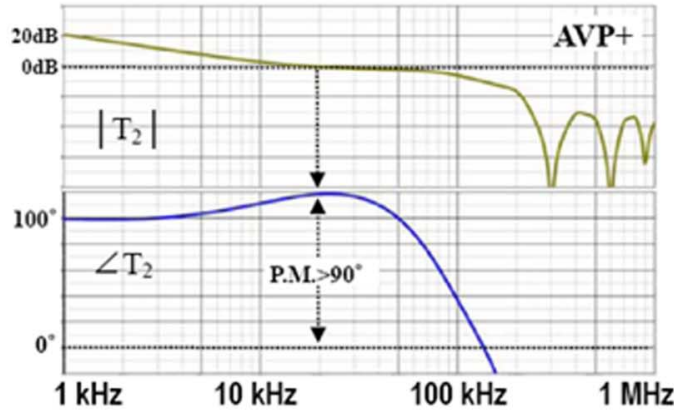

(a)

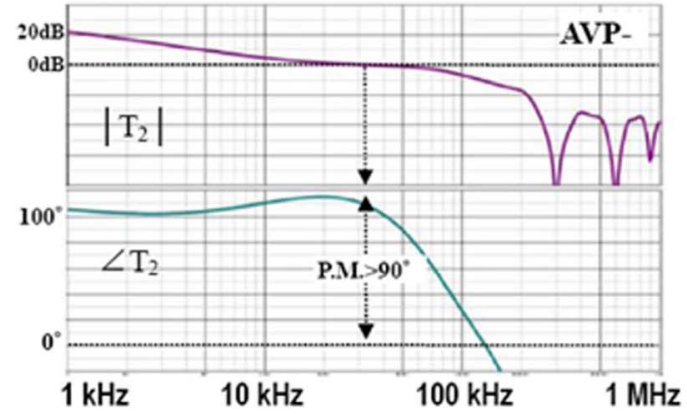

(b)

Fig. 20. Simulated $T_{2}$ of (a) AVP+ and (b) AVP- for case I.

occurs for AVP - starting to oscillate. The instability resulted in oscillation of the voltage and current waveforms.

\section{CONCLUSION}

An AVP+ control scheme was proposed and implemented for multiphase synchronous buck converter applications. A small-signal model was also developed for converters using this scheme. Based on the model, various compensation design issues were explored. The results are compared to a common-used AVP- scheme.

Depending on the relative location of the noise-suppressing compensation pole frequency with respect to the capacitor ESRzero frequency, the performance of converter output impedance $Z_{\text {oc }}$ and stability margin near the crossover frequency may vary a great deal. If the two frequencies are closer to each other, the 


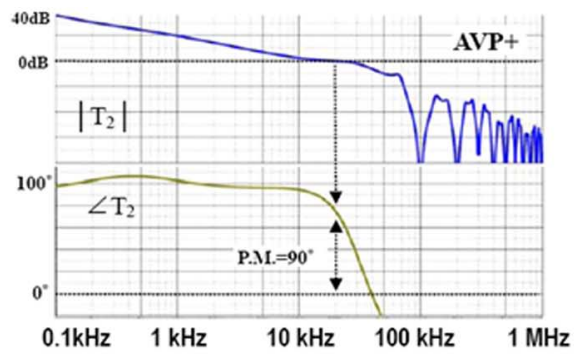

(a)

Fig. 21. Simulated $T_{2}$ of (a) AVP+ and (b) AVP- for case II

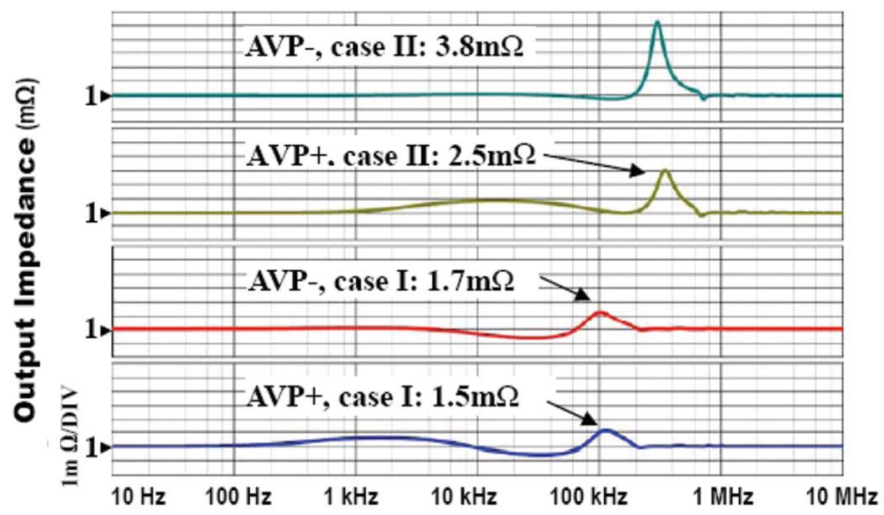

Fig. 22. Comparisons of $Z_{\mathrm{oc}}$ in SIMPLIS.

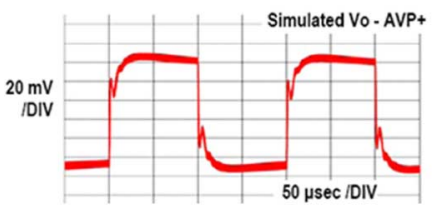

(a)

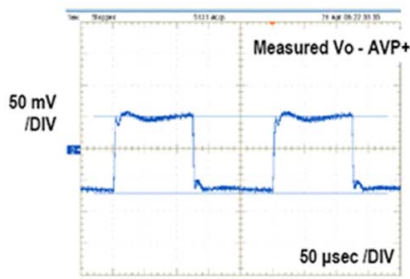

(c)

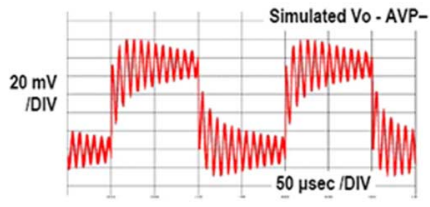

(b)

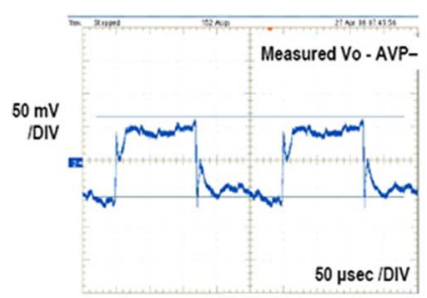

(d)
Fig. 23. Transient response waveforms for case II. (a) Simulated $\mathrm{V}_{o}$ for AVP+, (b) simulated $\mathrm{V}_{o}$ for $\mathrm{AVP}-$, (c) measured $\mathrm{V}_{o}$ for $\mathrm{AVP}+$, and (d) measured $\mathrm{V}_{o}$ for AVP. Test conditions: VID $=1.0 \mathrm{~V}$, load current step changed between 10 and $110 \mathrm{~A}$.

stability margin get smaller, and $Z_{\mathrm{oc}}$ is more likely to exhibit a spike/dip at the ESR frequency and step-load response gets overshoot. Compared to a conventional AVP- scheme, the proposed AVP+ shows superior performance especially when ceramic output capacitors are used. This is a significant advantage considering the trend of using ceramic capacitors in many future VRM applications.

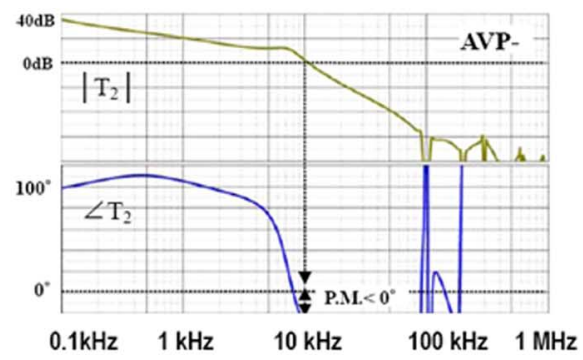

(b)

\section{ACKNOWLEDGMENT}

The authors would like to thank Transim Technology Corporation, Framingham, MA, for providing the SIMPLIS simulation software.

\section{REFERENCES}

[1] M. Zhang, "Powering Intel Pentium 4 processors," in Proc. Intel Technol. Symp., 2000, pp. 1-21.

[2] A. Waizman and C.-Y. Chung, "Resonant free power network design using extended adaptive voltage positioning (EAVP) methodology," IEEE Trans. Adv. Packag., vol. 24, no. 3, pp. 236-244, Aug. 2001.

[3] "VRM 9.0 dc-dc conveter design guidelines," Intel Document, Apr. 2001.

[4] Y. Ren, K. Yao, M. Xu, and F. C. Lee, "Analysis of the power delivery path from the 12-V VR to the microprocessor," IEEE Trans. Power Electron., vol. 19, no. 6, pp. 1507-1514, Nov. 2004.

[5] K. Yao, Y. Ren, and F. C. Lee, "Critical bandwidth for the load transient response of voltage regulator modules," IEEE Trans. Power Electron., vol. 19, no. 6, pp. 1454-1461, Nov. 2004.

[6] A. V. Peterchev and S. R. Sanders, "Load-line regulation with estimated load-current feedforward: Application to microprocessor voltage regulators," IEEE Trans. Power Electron., vol. 21, no. 6, pp. 1704-1717, Nov. 2006

[7] K. Yao, M. Xu, Y. Meng, and F. C. Lee, "Design considerations for VRM transient response based on the output impedance," IEEE Trans. Power Electron., vol. 18, no. 6, pp. 1270-1277, Nov. 2003.

[8] K. Yao, K. Lee, M. Xu, and F. C. Lee, "Optimal design of the active droop control method for the transient response," in Proc. IEEE APEC, 2003, pp. 718-723.

[9] K. Yao, Y. Ren, J. Sun, K. Lee, M. Xu, J. Zhou, and F. C. Lee, "Adaptive voltage position design for voltage regulators," in Proc. IEEE APEC, 2004, pp. 272-278

[10] "Microprocessor CORE voltage regulator two-phase buck PWM controller ISL6560 datasheet," Intersil document.

[11] "Dual-phase, quick-PWM Controller for IMVP-6 CPU Core power suppliers MAX8700 datasheet," Maxim document.

[12] "6-bit programmable 2-, 3-, 4-phase synchronous buck controller ADP3168 datasheet," Analog Devices document.

[13] "4/3/2/1-Phase PWM Controller RT8805 datasheet," Rictek document

[14] P. L. Wong, "Performance improvements of multi-channel interleaving voltage regulator modules with integrated coupling inductors," Ph.D. dissertation, Virginia Polytechnic Inst. and State Univ., Blacksburg, Mar. 2001.

[15] R. B. Ridley, B. H. Cho, and F. C. Lee, "Analysis and interpretation of loop gains of multiloop-controlled switching regulators," IEEE Trans. Power Electron., vol. 3, no. 4, pp. 489-498, Oct. 1988.

[16] Y. Qiu, J. Sun, M. Xu, K. Lee, and F. C. Lee, "Bandwidth improvements for peak-current controlled voltage regulators," IEEE Trans. Power Electron., vol. 22, no. 4, pp. 1253-1260, Jul. 2007.

[17] S. Chickamenahalli, K. Aygun, M. J. Hill, K. Radhakrishnan, K. Eilert, and E. Stanford, "Microprocessor platform impedance characterization using VTT tools," in Proc. IEEE APEC, 2005, pp. 1466-1469.

[18] B. Wang, S. Wang, D. Chen, K. Huang, B. Tai, and E. Tseng, "Practical simulation of control characteristics of a current-mode $\mathrm{dc} / \mathrm{dc}$ converter," in Proc. IEEE PESC, 2006, pp. 569-573. 


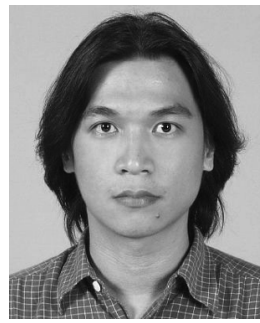

Martin Lee received the B.S.E.E. degree from National Taiwan University of Science and Technology, Taipei, Taiwan, R.O.C., in 1999 and the M.S.E.E. degree from National Taiwan University (NTU), Taipei, Taiwan, R.O.C., in 2003. He is currently pursuing the Ph.D. degree at NTU.

His research interest includes EMI, design and modeling of CCFL inverters, resonant converters, ballasts, LIPS, and VRMs.

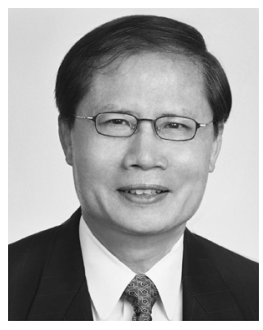

Dan Chen (M'79-SM'83-F'03) received the B.S.E.E. degree from National Chiao Tung University, Hsinchu, Taiwan, R.O.C., in 1969 and the Ph.D. degree from Duke University, Durham, NC, in 1975.

From 1975 to 1979 , he was with the GE Corporate Research Center, Schecnectady, NY, working on power electronics applications. From 1979 to June 2003, he was with the Electrical Engineering Department, Virginia Polytechnic Institute and State University (Virginia Tech), Blacksburg. He was a core faculty of the prestigious National Science Foundation Center of Excellency in Power Electronic Systems established at Virginia Tech from 1998 to 2003. Since September 2003, he has been with the Electrical Engineering Department, National Taiwan University, Taipei, as a Full Professor.

Prof. Chen has coreceived IEEE Aerospace Society Barry Carlton Award in 1975, and also coreceived the 1998 Society Best Paper Award of the IEEE Power Electronics Society.

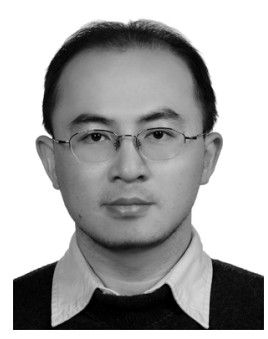

Kevin Huang was born in Tainan, Taiwan, R.O.C., in 1970. He received the B.S. and M.S. degrees in electrical engineering from National Tsing Hua University, Hsinchu, Taiwan, in 1993 and 1995, respectively. He is currently pursuing the Ph.D. degree in electrical engineering from National Taiwan University, Taipei, Taiwan.

After discharging military duty in 1997 , he was employed as a Technology Leader in the Delta Electronics Lighting Business Unit, where he worked on electronic ballast design from 1997 to 2000. From
2000 to 2007, he worked on analog and power IC design. He is currently a Manager with Richtek, Chupei, Hsinchu. He is currently leading a system and modeling team, the FAE and TME teams of the ac/dc department. His research interests includes power converter control and modeling, single-phase power factor correction, ac/dc power supplies, multiphase dc/dc buck converters, magnetic design, and power IC behavior modeling.

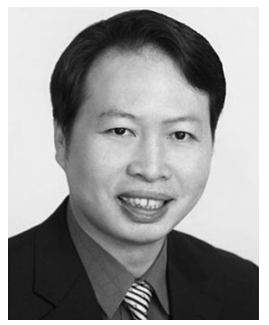

Chih-Wen Liu (M'96-SM'03) received the B.S. degree in electrical engineering from National Taiwan University (NTU), Taipei, Taiwan, R.O.C., in 1987 and the M.S. and Ph.D. degrees from Cornell University, Ithaca, NY, in 1992 and 1994.

He is currently a Professor in the Department of Electrical Engineering, NTU. His research area is in power systems, electric machine control, power electronics, and capsule endoscope magnetic controls.

Prof. Liu received the Outstanding Young Electrical Engineer Award from the Chinese Institute of Electrical Engineering in 2001, the Best Paper Award (Ten-You Jan Golden Medal) from the Chinese Institute of Engineers in 2002, Research Contribution Award from National Taiwan University in 2004, and the First Class Principal Investigator Award from National Science Council in 2005.

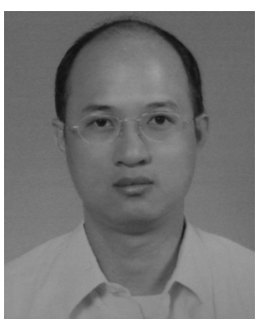

Ben Tai was born in Tainan, Taiwan, R.O.C., in 1965. He received the B.S. and M.S. degrees in electrical engineering from National Cheng Kung University, Tainan, Taiwan, in 1987 and 1989, respectively.

After discharging military duty in 1991, he joined Macronix International Company, Ltd., working on Mask ROM device characterization. Then in 1992, he transferred fields from device engineering to analog IC design. From 1992 to 1998, he worked on low dropout linear regulator (LDO) and dc-dc converter design with Analog Integration Comapny, Ltd. Since 1998, he has been with Richtek Technology Company, Ltd., Hsinchu, Taiwan, as a founder. He is the Vice Present of the Product Design Center (PDC) in Richtek. He leads an 80-person design team including system engineering and IC circuit design focusing on power management product development. 